\title{
Creutzfeldt-Jakob Disease and Homocysteine Levels in Plasma and Cerebrospinal Fluid
}

\author{
Stefan Bleich ${ }^{a}$ Markus Otto $^{b}$ Inga Zerr ${ }^{b}$ Stefan Kropp ${ }^{c}$ \\ Hans A. Kretzschmard Jens Wiltfang ${ }^{a}$ \\ aDepartment of Psychiatry and Psychotherapy, Friedrich-Alexander-University, Erlangen-Nuremberg, \\ bDepartment of Neurology, Georg-August-University Göttingen, cDepartment of Psychiatry and Psychotherapy, \\ Medical School University, Hannover, and Institute of Neuropathology, Ludwig-Maximilians-University, \\ Munich, Germany
}

\section{Key Words}

Creutzfeldt-Jakob disease - Cerebrospinal fluid • Homocysteine $\cdot$ Neurotoxicity $\cdot$ Neurodegeneration

\begin{abstract}
Background: There is evidence that homocysteine contributes to various neurodegenerative disorders. Objective: To assess the values of homocysteine in patients with Creutzfeldt-Jakob disease (CJD) in both cerebrospinal fluid (CSF) and plasma. Methods: Study design: Case control study. Total homocysteine was quantified in CSF and plasma samples of CJD patients $(n=13)$ and healthy controls ( $n=13$ ). Results: Mean values in healthy controls: $0.15 \mu \mathrm{mol} / \mathrm{l} \pm 0.07$ (CSF) and $9.10 \mu \mathrm{mol} / \mathrm{l} \pm 2.99$ (plasma); mean values in CJD patients: $0.13 \mu \mathrm{mol} / \mathrm{l} \pm$ 0.03 (CSF) and $9.22 \mu \mathrm{mol} / \mathrm{l} \pm 1.81$ (plasma). No significant differences between CJD patients and controls were observed (Mann-Whitney U, p > 0.05). Conclusions: The results indicate that the CSF and plasma of CJD patients showed no higher endogenous levels of homocysteine as compared to normal healthy controls. These findings provide no evidence for an additional role of homocysteine in the pathogenetic mechanisms underlying CJD neurodegeneration.
\end{abstract}

Copyright $\odot 2005$ S. Karger AG, Basel

\section{Introduction}

Elevated plasma homocysteine concentrations are linked to neuropsychiatric disorders such as alcoholism and alcohol-related brain atrophy [3], Alzheimer's disease (AD), and cognitive impairment [8]. Furthermore, increased plasma homocysteine levels are an independent risk factor for the development of $\mathrm{AD}$ [8]. Homocysteine is a neurotoxic excitatory amino acid, which plays a role in a shared biochemical cascade involving overstimulation of N-methyl- $D$-aspartate (NMDA) receptors, oxidative stress, activation of caspases, DNA damage, and mitochondrial dysfunction. These mechanisms are believed to be important in the pathogenesis of neurotoxicity and excitotoxicity $[3,6]$.

Prion diseases or spongiform encephalopathies are a group of fatal neurodegenerative disorders including Creutzfeldt-Jakob disease (CJD). Since the chemical composition of human cerebrospinal fluid (CSF) is considered to reflect brain metabolism, we investigated homocysteine levels in the CSF of CJD patients and healthy controls. Additionally, plasma samples were examined for total homocysteine levels. It was the aim of the present pilot study to assess the possible involvement of homocysteine in the pathogenesis of CJD.

\begin{tabular}{ll}
\hline KARGER & ( ) 2005 S. Karger AG, Basel \\
Fax +4161306 3234 -324X/05/0512-0142\$22.00/0 \\
$\begin{array}{l}\text { E-Mail karger@karger.ch } \\
\text { www.karger.com }\end{array}$ & $\begin{array}{l}\text { Accessible online at: } \\
\text { www.karger.com/ger }\end{array}$
\end{tabular}

\footnotetext{
Prof. Dr. Jens Wiltfang

Friedrich-Alexander-University of Erlangen-Nuremberg

Department of Psychiatry and Psychotherapy, Schwabachanlage 6-10

DE-91054 Erlangen (Germany), Tel. +49 91318534597

Fax +49 9131853 4105, E-Mail jens.wiltfang@psych.imed.uni-erlangen.de
} 


\section{Methods}

The present case control study was approved by the local Ethics Committee. Diagnosis of CJD and laboratory investigations were performed as previously described $[1,7,10] .13$ CJD patients were examined clinically by a member of the German CJD Surveillance Study Group and each patient underwent a detailed neurologic examination. The mean age of CJD patients was 65.8 years (range 53.8-83.5 years). All patients of this group have succumbed to their disease, and the diagnosis CJD was confirmed neuropathologically using immunohistochemistry for the prion protein in all cases. 14-3-3 protein was detected according to various methods $[7,10,11]$ in all 13 CJD patients. The controls consisted of 13 healthy subjects with normal cognition and without a diagnosis of any psychiatric or neurologic disease. After complete description of the study to the subjects, written informed consent was obtained. Controls were matched to cases by age and gender.

Screening for non-genetic factors possibly associated with elevated homocysteine levels such as lifestyle (alcohol abuse, nutritional status, medication), endocrinological conditions and other diseases (i.e. diabetes mellitus, cardiovascular diseases), laboratory methods and measurements (vitamins $B_{12}, B_{6}$ and folate) were performed on the basis of a previous study [2]. All patients and controls were classified as normally nourished (data not shown). Under these conditions, a plasma homocysteine reference interval of $4.9-11.7 \mu \mathrm{mol} / \mathrm{l}$ was defined as normal according to Ubbink et al. [9]. Normal ranges for CSF homocysteine are not known.

Total homocysteine in plasma and cerebrospinal fluid (CSF) was measured by an enzyme-linked immunosorbent assay (Axis ${ }^{\circledR}$ Homocysteine EIA, Germany/Norway, IBL-No. AX 513 01). Statistical analysis: The significance of differences between groups was evaluated by the non-parametric Mann-Whitney U test. Results are presented as the central tendency (mean) \pm SD. $\mathrm{p}<0.05$ (two-tailed) was considered to indicate statistical significance.

\section{Results}

As shown in figure 1, CSF as well as plasma homocysteine levels did not differ significantly between CJD patients $(n=13)$ and controls $(n=13)$. Central tendencies (CT or 'mean' \pm SD in $\mu \mathrm{mol} / \mathrm{l}$ ) in controls: $0.15 \pm 0.07$ (CSF) and $9.10 \pm 2.99$ (plasma); CT values in CJD patients: $0.13 \pm 0.03(\mathrm{CSF})$ and $9.22 \pm 1.81$ (plasma). Thus, no significant differences between CJD patients and controls in respect to homocysteine concentrations in samples of CSF $(Z=-0.46, p=0.65)$ and plasma $(Z=$ $-0.33, p=0.76$ ) were found. Furthermore, in both groups homocysteine concentrations were within the reference interval $(4.9-11.7 \mu \mathrm{mol} / \mathrm{l})$.

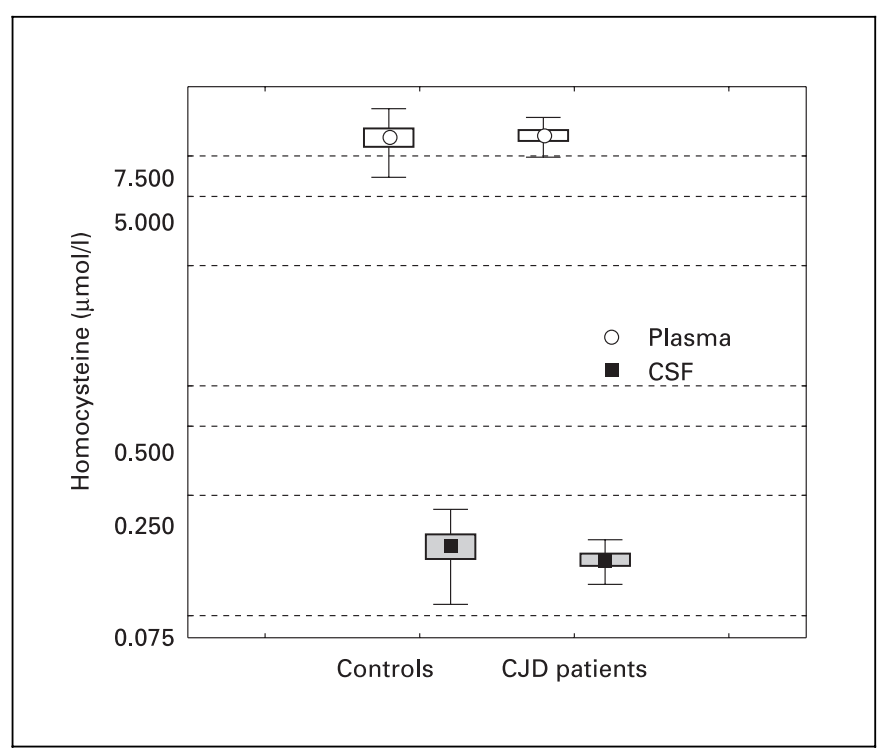

Fig. 1. Cerebrospinal fluid and plasma homocysteine levels in patients with CJD and controls.

\section{Discussion}

To our knowledge, this is the first study evaluating homocysteine levels in patients suffering from (sporadic) CJD. However, we did not detect any significant differences of homocysteine levels in CSF or plasma. A number of reviews detail acute or chronic pathophysiology in which free radicals and homocysteine express their toxicity in neurodegenerative disorders [5]. Taking into account that there is no evidence of oxidative stress in CJD patients [1] the results of the present study are in line with these previous observations. However, determining homocysteine levels in an earlier stage of CJD patients might deliver other results. Despite the identification of hyperhomocysteinemia as an independent risk factor for neurodegenerative disorders such as $\mathrm{AD}$ [8], little is known about the presence of homocysteine in the CSF. However, similar results were found in a recent study of 18 healthy adults with CSF homocysteine concentrations between 0.015 and $0.140 \mu \mathrm{mol} / 1$ [4].

Furthermore, it must be taken into account that an intracellular accumulation of homocysteine leads to hyperhomocysteinemia. Thus, the neurotoxicity of homocysteine is not only caused by an elevated extracellular homocysteine concentration, but especially by the toxic effects that can be triggered by the intracellular hyperhomocysteinemia and can affect the intracellular compartments [3]. 
Since we could not disclose an intracellular accumulation of homocysteine, further studies are needed which should be directed to CJD brain tissue. However, at this moment we conclude that homocysteine possibly does not play a pathophysiological role in CJD and may not serve as a biological marker of CJD but may be useful in the differential diagnosis of other neurodegenerative disorders, in particular AD.

\section{Acknowledgements}

This study was supported by a grant from the Federal Ministry of Health to H.A.K. and to S.P. (BMG Az325-4473-05/3). We are grateful to all colleagues from other clinics for their cooperation, which has enabled us to conduct the study in this way. We are especially obliged to Maya Schneider-Dominco and Monika Bodemer for technical assistance. This work is dedicated to our excellent colleague Prof. Dr. Sigrid Poser (MD), who died unexpectedly in July 2004.

\section{References}

1 Bleich S, Kropp S, Degner D, Zerr I, Pilz J, Gleiter CH, Otto M, Ruther E, Kretzschmar HA, Wiltfang J, Kornhuber J, Poser S: Creutzfeldt-Jakob disease and oxidative stress. Acta Neurol Scand 2000;101:332-334.

2 Bleich S, Jünemann A, von Ahsen N, Lausen B, Ritter K, Beck G, Naumann GO, Kornhuber J: Homocysteine and risk of open-angle glaucoma. J Neural Transm 2002; 109:1499-1504.

3 Bleich S, Bandelow B, Javaheripour K, Müller A, Degner D, Wilhelm J, Havemann-Reinecke U, Sperling W, Rüther E, Kornhuber J: Hyperhomocysteinemia as a new risk factor for brain shrinkage in patients with alcoholism. Neurosci Lett 2003;335:179-182.

4 Bottiglieri T: Folate, vitamin $\mathrm{B}_{12}$ and neuropsychiatric disorders. Nutr Rev 1996;54:382-390.
5 Halliwell B, Gutteridge JMC: Oxygen toxicity, oxygen radicals, transition metals and disease (review article). Biochem J 1984:219:1-14.

6 Lipton SA, Kim WK, Choi YB, Kumar S, D'Emilia DM, Rayudu PV, Arnelle DR, Stamler JS: Neurotoxicity associated with dual actions of homocysteine at the N-methyl- $D$-aspartate receptor. Proc Natl Acad Sci USA 1997;94:5923-5928.

7 Otto M, Wiltfang J, Cepek L, Neumann M, Mollenhauer B, Steinacker P, Ciesielczyk B, Schulz-Schaeffer W, Kretzschmar HA, Poser S: Tau protein and 14-3-3 protein in the differential diagnosis of Creutzfeldt-Jakob disease. Neurology 2002;58:192-197.

8 Seshadri S, Beiser A, Selhub J, Jacques PF, Rosenberg IH, D'Agostino RB, Wilson PW, Wolf PA: Plasma homocysteine as a risk factor for dementia and Alzheimer's disease. N Engl J Med 2002;346:476-483.
9 Ubbink JB, Becker PJ, Vermaak WJ, Delport $\mathrm{R}$ : Results of B-vitamin supplementation study used in a prediction model to define a reference range for plasma homocysteine. Clin Chem 1995;41:1033-1037.

10 Zerr I, Bodemer M, Weber T: The 14-3-3 brain protein and transmissible spongiform encephalopathy. N Engl J Med 1997;336:874.

11 Zerr I, Pocchiari M, Collins S, Brandel JP, de Pedro Cuesta J, Knight RS, Bernheimer H, Cardone F, Delasnerie-Laupretre N, Cuadrado Corrales N, Ladogana A, Bodemer M, Fletcher A, Awan T, Ruiz Bremon A, Budka H, Laplanche JL, Will RG, Poser S: Analysis of EEG and CSF 14-3-3 proteins as aids to the diagnosis of Creutzfeldt-Jakob disease. Neurology 2000;55:811-815. 